\title{
A ANOMALIA DEMOCRÁTICA: \\ adolescência e romantismo na história política*
}

\section{Wanderley Guilherme dos Santos}

Há 20 anos atrás nós nos congregamos, ainda sob regime militar, e fundamos esta associação com o compromisso que então tínhamos, e que estou certo que ainda temos, com a liberdade. Não apenas com a liberdade exterior, aquela que mais imediatamente nos ameaçava, que nos acorrentava efetivamente, a todos, a muitos de nós, e a muitos dos que não estão mais aqui, mas também com a liberdade interior, a liberdade de ousar, a liberdade de ter coragem de pensar, de refletir, de experimentar. Efemérides são insípidas se não nos recordamos dos motivos que as provocaram. Esta efeméride foi provocada por um compromisso com a liberdade, há 20 anos atrás.

Mas não foi a única efeméride no caminho da liberdade humana. Há 50 anos atrás, em 1947, recém-inaugurada a democracia brasileira, o Partido Comunista e os comunistas foram postos na ilegalidade política neste país. Há cem anos atrás extinguiu-se Canudos. Há 130 anos, em 1867, José de Alencar escreveu as Novas Cartas de Erasmo, e talvez para surpresa de alguns nelas ele mostrava como o Brasil podia se libertar da escravidão. Há 377 anos, em 1620, o
Mayflower zarpava da Inglaterra em direção ao que deveria ser a Nova Inglaterrra, que não foi. Há 397 anos, em 1600, Giordano Bruno foi queimado em praça públca em Roma porque disse não. Eram tempos em que a autocracia, como a rainha do país das maravilhas de Alice, cortava cabeças por toda a Europa. Chicoteva, prendia, executava, soberba, arrogante, altaneira, fria, gelada. Colhi no livro de Cesario Verde umpalimpsesto que, creio, ele fez pensando na autocracia monárquica arrogante que então, no início do século XVII, acorrentava a Europa:

Quando passa, aromática e normal, com seus gestos de neve e de metal, eu vejo-a com real solenidade e tão alta e serena como a morte. Grande dama fatal, sempre sozinha, concebe o gelo como esposo, sem sorrisos, dramática, cortante. Mas cuidado, mi Lady, os humilhados para a vingança aguçam os punhais, e ou vai alguém morrer, ou vão matar alguém.

De fato, o século XVII, assim como o século XVIII, testemunhou trovões, relâmpagos, raios, mortes, 
execuções, enforcamentos, não só de humilhados e ofendidos, mas de reis e rainhas também. Naqueles tempos de liberdade, a autocracia reprimia mas ao mesmo tempo compreendia que estava em jogo o seu destino. Na década de 40, no século XVII inglês, num sopro de rebelião, extingue-se a Câmara dos Lords, proclama-se a república, expulsa-se o rei, mas também cassam-se mandatos na Casa dos Comuns, e impede-se os deputados de parlamentar.

O que eu desejo compartilhar com os meus colegas esta noite são reflexões sobre algumas dimensões, alguns momentos da história desta liberdade exterior e desta liberdade interior, e um pouco dos problemas que afligem aqueles que sabem dizer não. Eu gostaria de fazer isso abordando três temas.

Primeiro: existe um problema político fundamental que se colocou a partir do século XVII e que não foi resolvido ainda, nem mesmo pela democracia; esse problema é o problema dos irredentos, o problema daqueles que mantêm a afirmação de que não abdicam do direito de que não podem ter o direito de abdicar do direito de serem livres. E que, portanto, a qualquer momento que julguem necessário, poderão dizer não e negar que o império das instituições os compreenda e os esgote, não apenas na sua liberdade exterior, mas também, e fundamentalmente, na sua liberdade interior. O problema dos irredentos não foi resolvido por nenhuma teoria política e por nenhum sistema político, senão pela força.

Segundo: mesmo com uma definição minimalista de democracia, esta é um rebento recém-nascido na história política dos povos. E o terceiro: a origem do problema insolúvel do irredentismo é a mesma origem da democracia, e por isso ele não é solúvel senão com mais democracia, que o repõe, que exige mais democracia. Essa origem é a impossibilidade de exaurir-se a subjetividade humana quando ela se descobre livre.

Eu não tenho a oferecer aos colegas senão um roteiro, talvez não o melhor, talvez não o mais efetivo, mas o roteiro que escolhi para compartilhar com vocês esta noite, nesta celebração do irredentismo libertário.
É reconhecido que o romantismo redescobre a subjetividade humana, algo que havia sido, supostamente, ofertado à humanidade como prêmio por Descartes. O cogito cartesiano teria sido redescoberto pelo romantismo. Nesse juízo concorrem todos os grandes críticos literários, e eu vou reduzir ao máximo citações, referências, para não cansá-los. Entretanto, na realidade, não é a subjetividade cartesisana que o romantismo inaugura. Não é o sujeito cartesiano do cogito, ergo sum que o romantismo reivindica e afirma perante as instituições, perante a ordem, perante a rotina, perante o cotidiano. Há, conforme os críticos do romantismo, aqueles que consideram que existe uma neurastenia romântica caracterizada por dois princípios: pela hipertrofia da sensibilidade e pela hipertrofia da imaginação. É verdade. Mas não é a subjetividade, nem a sensibilidade, nem a imaginação de Descartes que se afirma, como Baudelaire nos seus paraísos artificiais, emum comedor de ópio,o seguinte palimpsesto:

O que é importante é que as coisas sejam criadas; elas sendo criadas, elas são. E aquele que as cria, cria uma coisa que tem um caráter indestrutível. No espiritual, não mais do que no material, nada se perde, da mesma maneira que toda ação lançada no turbilhão da ação universal é em si irrevogável e irreparável, abstração feita de seus resultados possíveis, da mesma maneira que todo pensamento é inapagável. O palimpsesto da memória é indestrutível.

Essa subjetividade que cria, que gera idéias irreparáveis, inapagáveis, não é a subjetividade cartesiana, como não é cartesiana a reflexão do romântico Rimbaud sobre si próprio:

Digo que é necessário ser vidente, se fazer vidente, através de longo, imenso e refletido desregramento de todos os sentidos. Ele, o poeta, todas as formas de amor e sofrimento, de loucura. Ele, o poeta, procura a si mesmo e esgota em si todos os venenos, não retendo senão a quintessência, inefável tortura que requer toda a fé, toda força sobre-humana, e na qual ele se converte, entre todos, no grande doente, grande criminoso, grande maldito e supremo sábio, porque atingiu o desconhecido. Quero ser poeta e trabalho para me tornar vidente. Trata-se de 
alcançar o desconhecido pelo desregramento de todos os sentidos. Os sofrimentos são enormes e é necessário haver nascido poeta. É falso dizer "penso". Devia-se dizer: "pensam-me". Ou Novalis: "Neste estado, é menos o sujeito que percebe os objetos do que, inversamente, os objetos que vêm perceber-se no sujeito".

Essa subjetividade não é cartesiana porque a subjetividade que se expressa no cogito, ergo sum é fonte de errro, é submissa aos limites da finitude perante Deus. Ela conhece aquilo que não pode jamais conhecer; ela sabe de antemão o que não sabe. A subjetividade romântica é anticartesiana e se expressa em algumas posições: não se conhece $a$ priori os limites da subjetividade, nem por estrita exploração racional; os limites da subjetividade, se existem, estão ao final do desregramento de todos os sentidos; o mundo não é um dado, mas se cria, como disssera Rimbaud 30 anos antes; e o que se cria é imortal, por irreparável, e a origem dessa criação encontra-se na subjetividade inesgotável.

A relação entre o interior e o exterior proposta pelo romantismo seguramente não é a subjetividade cartesiana. É em Kandinski, na espiritualidade da arte, no ponto e reta sobre plano que vamos encontrar as reflexões sobre aquilo que se gera no interior e aquilo que é o exterior, sobre como se conhece o exterior através do interior, sobre como é impossível conhecer o exterior senão através do interior.

O que diz Kandinski? O que é o exterior? Exterior é aquilo que eu percebo, mas o que eu percebo eu percebo como interior. E o que é o interior? Eu só conheço o meu interior, eu só posso conhecer o meu interior, na medida em que eu o expresso; mas quando eu o expresso, eu já o expresso comprometido com a matéria do mundo. Eu o expresso como exterior. Para conhecer o interior, para qualquer um conhecer o meu interior, só através da sua expressão como exterioridade, porque o interior enquanto tal é incognoscível. Isto é Kant. Esta é a subjetividade póskantiana. Esta é a subjetividade que inventa o mundo ao percebê-lo e que precisa inventar o mundo para perceber qual é o conteúdo de sua própria subjetividade, de seu próprio pensamento, das suas próprias condições de possibilidade de conhecer, e conseqüentemente de fazer juízos, e conseqüentemente de fazer valorações, e conseqüentemente de agir. Esta subjetividade é uma subjetividade que inventa o mundo, e inventando o mundo inventa a cultura. Só é possível conhecer a minha cultura quando eu tento conhecer a cultura alheia e percebo que a minha forma de conhecer a cultura alheia é a forma que eu tenho de verificar de que maneira a minha própria cultura se objetifica, se objetiva, se torna exterior. Isso não é mais Kandinski, isso é Roy Wagner, antropólogo, em The invention of culture.

Esse mundo criado pela interação permanente entre a experimentação interna, a manipulação dos materiais que a experiência me dá, a experimentação permanente, é um mundo irreparável, irrevogável, inapagável. E é um mundo que se estrutura conforme um código altamente elaborado e sofisticado, não de matéria bruta, não de pensamento abstrato bruto, não de um cogito vazio, mas de um conjunto de símbolos, ou melhor dizendo, de uma floresta de símbolos - que não por acaso é o título de um livro de Victor Turner, mas também parte de um verso do maravilhoso soneto "Les correspondences", de Baudelaire, de onde Victor Turner tirou a expressão.

A conexão cartesiana, finalmente, afirma que a fonte do conhecimento é a intensidade da convicção com que temos a certeza de alguma percepção, porque se não fora esta intensidade de nossa própria subjetividade, nós não teríamos outra fonte de reconhecimento da verdade, uma vez que a subjetividade é fonte apenas e somente de erro. Esta é a subjetividade cartesiana. A única forma de discernir um ato criativo da subjetividade, verdadeiro, de um ato criado por uma subjetividade que não consegue se exteriorizar é pela intensidade da convicção. Isso se encontra na primeira e na quarta Meditações metafísicas de Descartes. Conclusão: a infinitude da subjetividade romântica, a sua inesgotabilidade, a sua necessidade de materialização, obriga à permanente transcendência de si mesma, a uma busca de seus próprios limites e a uma experimentação continuada. A impossibilidade de saber $e x$ ante até onde pode ir a criação e a geração de símbolos leva à experimentação de formas, de fórmulas de interações, de 
modos de convivialidade social, de modos de interação, de modos de conhecer. Só fazendo é possível conhecer.

O romantismo restaurou a verdade da desmedida, dabybris.Como diz Meckron — e Meckron é um crítico o romantismo conduz as pessoas a ficarem em desproporção não somente em relação ao seu ambiente, mas consigo mesmas. Esta a neurastenia romântica, segundo ele. Mas, de acordo com Moses Peckham, nisto consiste a virtuosidade romântica. O romantismo é a busca permanente da transcendência, um impulsionar permanente para a frente, pela impossibilidade de conhecer a priori quais são os limites da experimentação humana, pela negação de que seja possível reconhecer antecipadamente o que é que nos limita, o que eu não posso conhecer. E se verifica nisso uma contradição em termos. Como pode a ignorância saber-se a si mesmo até que ponto ela é ignorante, como Pascal desejava? Só é possível conhecer a extensão do romantismo, a extensão da subjetividade, experimentando a sua superação, experimentando transcender-se não no sublime, no sublime divino, mas transcender-se no humano, transcender-se em outras obras, transcender-se para frente, nos experimentos, na novidade. Por conta dessa transcendência permanente, obrigada pela própria concepção de si mesma, em busca de si mesma, como vidente que se quer ver através dos experimentos de dersregramento de todos os sentidos e de todas as emoções, o romantismo é inacabável, como curiosamente são inacabadas todas as grandes obras românticas. Le livre, de Mallarmé, jamais foi terminado. O grande poema romântico de Victor Hugo, "La fin de Satã", começado em 1856, jamais foi terminado (foi publicado postumamente em 1886). E Rimbaud, ele próprio, antecipando a filosofia contemporânea, calou-se quando não teve mais, poeticamente, a possibilidade de transcender-se.

De modo que a recuperação, o restabelecimento da subjetividade romântica nada tem a ver com o cartesianismo. No início do século, um poeta sevilhano, Antonio Machado, dizia em um de seus cantares: "Já houve quem pensou: cogito, ergo num sum.Que exagero!". Não, não era exagero! Os românticos diziam exatamente isso: "Nós vivemos e não podemos ainda, enquanto não esgotarmos o experimento da subjetividade de suas criações, enquanto não provarmos os seus limites, a impossibilidade de gerar novas formas de convivialidade, de novas expressões de arte, nova musicalidade, novos seres, novos amores, novas paixões, novas sensualidades. Enquanto não formos capazes de realmente chegar ao fim de Satã, o romantismo é infindável, porque ele é cotérmino à subjetividade humana, se ela é infindável e inexaurível.

Eu estou começando o meu roteiro de maneira inversa. $\mathrm{O}$ que tem a ver o romantismo com a democracia? É impressionante e talvez surpreendente para nós, estudiosos da democracia, respeitosos dos grandes teóricos e pensadores clássicos e contemporâneos, e entre eles incluo por exemplo Robert Dahl, termos dificuldade com a cronologia, a cronologia do que seria ou do que teria sido a evolução da democracia. Vou-lhes dar uma definição minimalista de democracia: chamemos democracia aquele sistema em que o poder é preenchido após eleições regulares, em condições de sufrágio universal e sob garantias mútuas, ou seja, de respeito pelos resultados. Ora, essa definição minimalista de democracia, que requer não apenas eleições regulares e respeitadas mas também sufrágio universal, não pode ser aplicada da maneira tão fácil, tão simples, tão gratuita, tão generosa com que se a aplica à cronologia da história política a partir do seculo XVII, e a partir do século XVIII, e a partir do século XIX. Até mesmo porque poder preenchido mediante eleições regulares, com segurança mútua e com sufrágio universal só ocorreu em 1893 na Nova Zelândia; em 1902 na Austrália; em 1913 na Noruega; em 1915 na Dinamarca; em 1919 na Alemanha e na Holanda; em 1921 no Canadá e na Suécia; em 1923 na Irlanda; em 1929 na Inglaterra.

Enfim, o sufrágio universal só ocorre no mundo no início do século XX. O direito de voto a todo adulto, homem e mulher, independentemente de sexo, religião, renda, cor, só começa a ocorrer a partir do início deste século. A última barreira a ser superada — nestes grilhões que acorrentavam a participação e a criação de formas políticas novas, formas que a humanidade começará a experimentar depois que os reis são decapitados, nos séculos XVII e XVIII — foi o 
voto feminino. Caem - e eu tenho a cronologia de quando caem, dos impactos que tiveram na vida política — os requisitos de renda, de religião, de idade (25-26 anos), de estado civil, de cor, os requisitos de sexo. Todos eles foram sendo sucessivamente abolidos ao longo do século XIX. Evoluía o sistema representativo, que substituiu o sistema monárquico autocrático. Não evoluía o sistema democrático; evoluía o sistema representativo oligárquico. E com a abolição de cada uma dessas barreiras aumentava a população, a comunidade política.

Mas o voto feminino, seu impacto na comunidade política, foi extraordinariamente revolucionário. Se somam, com freqüência, o fim do requisito de renda e do requisito de sexo, mas nas primeiras eleições que se sucederam à instalação do voto universal, este foi o crescimento percentual da comunidade política nos vários países: 66\% na Nova Zelândia, 92\% na Austrália, 34\% na Noruega, 148\% na Dinamarca, $158 \%$ na Alemanha, 117\% na Holanda, 112\% no Canadá, $170 \%$ na Suécia, 25\% na Irlanda, 33\% na Inglaterra. Ou seja, a democracia é uma revolução.

Nós estamos tratando de um outro mundo, de um mundo em que nenhuma das formas institucionais até então vigentes tinha resposta para um problema que se supunha resolvido, mas que só se resolveu no século XVII inglês, no século XVIII francês e americano. Esse problema, fundamental, era o seguinte: ao se reconhecer que o poder constituinte do poder residia no povo soberano, como devia ele governar-se? Como podia parte do povo — os representantes - governar todo o povo, os governados? Até onde poderia ir o direito de impor decisões àqueles que não haviam concordado sequer com a constituição de um sistema representativo, que são os irredentos? Aqueles que não assinaram o contrato original que os leveller ingleses achavam que todos os ingleses deviam assinar para que o sistema fosse legitimamente representativo; aqueles que se resguardavam o direito de só cumprir aquilo a que dessem consentimento, como poderiam eles ser governados por aqueles cujo poder vinha de sua própria delegação? A distinção entre poder constituinte e poder legislativo - o que significa um sistema representativo? quem representa o que? até que ponto? com que direito? - é um problema que perpassará todo o século XVII inglês, todo o século XVIII, praticamente, inglês, todo o século XVIII americano e todo o século XVIII e XIX francês, em que se concedeu e retirou o sufrágio universal e experimentou ditaduras várias vezes a partir de 1792 .

A história inglesa e a história americana durante os dois séculos a que me referi é a história de um ajuste entre o que significava um sistema representativo, o que implicava em termos de abdicação de direitos por parte daqueles que reconheciam o sistema instaurado, até onde podiam ir os representantes na sua decisão de impor legislação. E o princípio da segurança mútua traduzido nestes séculos queria dizer o seguinte: ninguém pode delegar a outro um direito que não possui: o direto de impor a terceiros uma decisão de que terceiros discordam. Portanto, o limite da imposição de decisões legislativas era a capacidade de efetivamente impor aos irredentos o império do sistema representativo, por delegação de parte dos representantes. O problema do século XVII inglês e do século XVIII inglês e americano não é um problema de participação. $O$ problema político dos séculos XVII e XVIII inglês e americano é um problema de autonomia, de independência. Em primeiro lugar, do parlamento diante do rei. É por isso que se decapitam reis, para que eles aceitem a idéia de que existe limites ao seu poder de impor coisas ao parlamento que representa o povo. Mas que povo é esse? Em nome de um abstração — do que é o povo em geral - se impõe a uma parte do povo aquilo que, teoricamente, o povo em geral, por delegação, deu a esses representantes. O que ocorre durante os séculos XVII e XVIII é um disputa em torno da autonomia do parlamento, portanto, da sua independência em relação aos ditames do rei, e depois, em torno da autonomia do indivíduo em relação ao sistema político, o direito que cada indivíduo deveria, ou não, continuar a ter de dizer: "não faço parte do pacto, quero conviver em sociedade, quero me relacionar com os meus iguais, mas não desejo nem necessito aceitar leis com as quais eu não concordo. Eu não quero ingressar no pacto político". O problema político dos séculos XVII e XVIII não é um problema de participação, é justamente o 
contrário: o direito de não participar do pacto político se eu não desejar, de não delegar soberania e de não aceitar que os representantes tenham império sobre toda a sociedade à qual pertenço e da qual dependo.

Ao longo desses dois séculos essas questões foram sendo interpretadas, institucionalizadas e aceitas pela comunidade. Ou seja, o parlamento mobilizou muitos grande parte do povo — para dar poder a poucos — os representantes - para governar muitos - a maioria, todos. Este problema, uma vez resolvido, passou a significar que aqueles que desejavam manter o direito de autonomia ou bem faziam parte da comunidade política e aceitavam o império do parlamento, ou restavam anômicos — sem lei, na ilegalidade — e sobre eles podia se exercer todo o direito dos representantes do povo em abstrato.

No momento em que não há mais lugar na sociedade, em princípio, para se esconder os irredentos - e isso ocorre quando os exércitos oficiais institucionalizados tornam-se mais poderosos do que os indivíduos ou pequenos grupos de indivíduos (não esquecer que durante os séculos XVII e XVIII os exércitos oficiais não existiam, que cada um possuía as suas armas, que cada pequena comunidade podia se armar e resistir), quando o poder dos representantes torna-se suficiente para impor pela força o seu império como se soberania fosse, e não apenas lei —, cessa o problema da independência do ponto de vista teórico e para a maioria se coloca o problema da participação. Institucionalizar as relações políticas significava, simultaneamente, definir a inclusão e a exclusão.

Não obstante, do ponto de vista legal, embora somente pudessem eleger e ser votados os adultos homens, casados, acima de um certo nível de renda, religiosos — protestantes ou católicos —, brancos etc. etc., apesar de serem estes os eleitores, a participação política durante os séculos XVII e XVIII era uma festa. O processo eleitoral obrigava os candidatos a percorrerem as cidades, a ouvirem as petições e as demandas do povo, a escutarem suas reclamações. Todos interpelavam os candidatos, embora apenas alguns votassem. Era uma festa, um carnaval, a inversão de papéis: a ficção da igualdade de todos perante o poder. E essa ficção era fundamental: inventou-se o povo para dar legitimidade ao poder institucionalizado. A democracia que se vai constituir é, na verdade, o alargamento da participação no sistema representativo oligárquico. A democracia institucionalizada é a negação da democracia romântica, que é a participação de todos, a festa revolucionária, como chama Mona Ozouf. E a grande festomania terminou, diz ela, com uma grande decepção. Porque à medida que se institucionalizava a participação, à medida que as demandas por participação foram sendo aceitas, o que se institucionalizava e o que se fazia simultaneamente era a exclusão legal dos irredentos e daqueles que a inclusão deixava de fora.

Pois o grande ato da reforma de 1832 na Inglaterra, além de aumentar o eleitorado reduzindo o censo, ou seja, o requisito de renda para a participação política - o que ampliou o eleitorado de 2,5\% para 3,6\% do total da população - , foi ao mesmo tempo tornar ilegal as paradas e os carnavais no processo eleitoral, obrigando à existência de cabines, a que só entrassem para discutir com os candidatos aqueles que tinham o direito de votar. E a grande festomania revolucionária da participação transformou-se na exclusão. Pois o grande ato da reforma de 1867 na Inglaterra, que dimunuiu outra vez o requisito de renda e permitiu o aumento da participação para pouco mais de $6 \%$ da população inglesa, foi a exigência de que os candidatos fossem filiados a partidos, de que os partidos fossem institucionalizados, de que só aqueles que fossem filiados a partidos participassem do processo. A institucionalização da participação foi ao mesmo tempo a institucionalização da exclusão. Não foi possível institucionalizar, organizar a participação política sem, simultaneamente, dizer quem ficava fora do jogo da representação oligárquica. E com o sistema representativo, e com essa institucionalização na Inglaterra, nos Estados Unidos, vieram, como vieram no Brasil no século XIX, como vieram na Nova República, a violência, a corrupção endêmica, a fraude, a compra de votos, as tentativas, às vezes com sucesso, de impeachment de representantes. Tudo isso veio com a extensão da participação política. 
Ao final desse processo, quando todas as barreiras são abolidas, nós encontramos que a democracia institucionalizada é uma forma recentíssima - como vimos, a partir do início do século, e para alguns países como a Inglaterra a partir do final da década de 20 - de conciliar a autonomia dos irredentos, dos indivíduos, com a imprevisibilidade de um modo material de produção comercial e industrial cuja temporalidade é inteiramente diferente da temporalidade do modo de produção agrário, durante o qual as eleições eram simultaneamente festas de participação. O calendário, o ritmo e a expressividade das festas e ritos de celebração de contratos do sistema mercantil, comercial e industrial, são outros, radicalmente distintos daqueles dos ritos de celebração de contratos nas sociedades agrárias. Receitas para a formação de identidades sociais; eleições; conteúdo, extensão e limites do mandato representativo; em nome de quem se fazem as leis; as bases de sua legitimidade; a abrangência do direito de impor sem consentimento: tudo se altera, tudo se torna imprevisível, e é a isso que é preciso dar previsibilidade.

Um novo palimpsesto nos mostra que, na verdade, ao se expandir a participação política, ao se alargar os limites do sistema representativo oligárquico, se instaura no mundo a imprevisibilidade das formas de participação e a imprevisibilidade dos resultados. Sóror Violante do Céu nos dá, em outro palimpsesto, uma antecipação do que então se instaura na sociedade, aqui, na democracia institucionalizada, onde já fenecem por decreto, entre as certezas de um logo, as incertezas de um quando, no Parnaso Lusitano de 1733, mas isso só aconteceu ao final do século XIX.

O fundamento da ficção que funda o governo e dá previsibilidade não está na narrativa mimético-cartesiana, mas na metáfora contrapositiva de Levi-Strauss: a afirmação de uma identidade simbólica (o povo) para esconder uma diferença real (as classes) e a afirmação de uma diferença simbólica (representantes/representados) para esconder uma identidade real (os produtores de poder).
E quem são os produtores de poder? A congregação comunitária permanentemente fundante e sempre correndo o risco de não aceitar o império da institucionalidade. Os produtores de poder, hoje, como sempre, são aqueles que não abdicam de afirmar que o poder constituinte é algo que não se transfere, que há uma distinção entre poder constituinte e poder legislativo, e que se foi a subjetividade que levou à democracia, também é essa subjetividade que impõe permanentemente a necessidade de novos experimentos, de novas formas de interação, de novas reflexões sobre o que ocorre, de propostas utópicas; que impõe a liberdade interna de pensar, de ousar e de tentar instaurar a quebra de rotina. Os produtores de poder são os irredentos de sempre, são os irredentos de hoje, submetidos pela força, pela ameaça da coação, mas que jamais abdicaram da sua liberdade interior, nem mesmo quando privados da sua liberdade exterior. São esses irredentos, é a esses irredentos, é nesses irredentos que se funda o impulso permanente para a transcendência humana de si próprio a cada momento histórico; neles e não nos conformados, nos submissos, nos rotinizados; é nos irredentos, nos que dizem não à arrogância do poder, nos que dizem não à altivez do poder, nos que dizem não à unanimidade do dogmatismo, das opiniões hegemônicas, nos que dizem não, nos que dizem não, nos que dizem não! Só estes é que, a cada momento, transcendem e têm a coragem e a ousadia de tentar transcender o dado, o institucionalizado, de desprezar e não se intimidar com o estigma, com a discriminação, com o ostracismo, com a difamação, com a calúnia, com a infâmia, com o assassinato de caráter. É nos irredentos que sempre se fundou, sempre se funda e sempre se fundará a democracia. Ela, que está em sua adolescência romântica.

Eu quero deixar o meu agradecimento aos meus colegas que me convidaram, pela distinção. E eu quero deixar meu voto pelos irredentos com uma ode, que tem dois títulos: "Oh demoníaca autonomia", é um título, e "Ode maníaca à autonomia", é o outro título:

\section{Ave demomaria}

Cheia desgraça, senhor é confisco

Bem-feita sois vós, entre as melhores, 
Bem-feita é a frente de vossa fronte, em luz

Senta Maria, mãos de adeusdemos

Roçai por nós, eleitrovadores

Senhora, que ora de mim consorte,

Amei.

* Conferência proferida no XXI Encontro Anual da Anpocs, Caxambu, outubro de 1997. 